\title{
Anterior ischaemic optic neuropathy and intraocular pressure
}

\author{
B Katz, R N Weinreb, D T Wheeler, M R Klauber
}

\begin{abstract}
Anterior ischaemic optic neuropathy is a stroke syndrome of the distal optic nerve, characterised by disc oedema and optic nerve dysfunction - loss of central vision, loss of colour vision, a relative afferent pupillary defect, and nerve fibre layer field loss. We prospectively evaluated the changes of intraocular pressure throughout the day in 16 patients with non-arteritic anterior ischaemic optic neuropathy and 15 normal control subjects of similar age and race. The peak intraocular pressure exceeded $21 \mathrm{~mm} \mathrm{Hg}$ in five of the ischaemic optic neuropathy patients but none of the controls. The mean peak intraocular pressure was $19.9 \mathrm{~mm} \mathrm{Hg}$ for the ischaemic optic neuropathy group versus $17.6 \mathrm{~mm} \mathrm{Hg}$ for controls $(p=0.034)$. The range of intraocular pressure was also greater for the ischaemic optic neuropathy group $(\mathbf{p}=\mathbf{0 . 0 3 0})$. Eight of 16 ischaemic optic neuropathy patients had a range of intraocular pressure of $6 \mathrm{~mm} \mathrm{Hg}$ or more, compared with three of 15 control subjects. The intraocular pressure exceeded $21 \mathrm{~mm} \mathrm{Hg}$ during a subsequent visit in two additional patients in whom the hourly determined intraocular pressure peaked at less than $21 \mathrm{~mm} \mathrm{Hg}$. Thus, seven of 16 of our ischaemic optic neuropathy group had an intraocular pressure exceeding $21 \mathrm{~mm} \mathrm{Hg}$ during the study period. Raised intraocular pressure may be a predisposing factor in some patients who develop anterior ischaemic optic neuropathy.
\end{abstract}

Anterior ischaemic optic neuropathy is a syndrome consisting of sudden loss of peripheral or central vision, or both, associated with optic disc swelling and, commonly, peripapillary nerve fibre layer haemorrhage. ${ }^{\prime}$ Patients experience a sudden loss of vision that may be progressive over days but is stable thereafter. Vision may improve, and recurrences in the same eye are rare. ${ }^{1}$ It is associated with a number of vasculitides, including giant cell arteritis and systemic vasculopathies as well as haematological and ocular disease. Most patients with ischaemic optic neuropathy, however, are otherwise healthy or have hypertensive atherosclerotic disease.

Factors which predispose certain eyes to develop ischaemic optic neuropathy have been recognised. ${ }^{24}$ For example, an eye with a congenitally crowded and small optic disc, with small cup-disc ratio, may be anatomically predisposed. Although the relationship between ischaemic optic neuropathy and elevations of intraocular pressure has been alluded to by several investigators, ${ }^{5-16}$ it has not been defined.
Foulds identified raised intraocular pressure in $29 \%$ of patients with ischaemic optic neuropathy. ${ }^{6}$ Raised intraocular pressure has been suggested as contributing to the pathological changes in the optic disc when ischaemic optic neuropathy follows cataract extraction, ${ }^{1+}$ precipitating an imbalance between the intraocular pressure and the perfusion pressure of the posterior ciliary arteries and, consequently, in the perilaminar capillaries. Despite such observations, contributions of high intraocular pressure to the development of idiopathic ischaemic optic neuropathy have been largely ignored.

In the present study we prospectively evaluated the changes of intraocular pressure throughout the day in patients with non-arteritic ischaemic optic neuropathy and control subjects of similar age and race. The ischaemic optic neuropathy patients were further studied to record their intraocular pressure during routine office visits in the course of their continuing care.

\section{Material and methods}

Sixteen consecutive patients with non-arteritic ischaemic optic neuropathy were prospectively studied from a consultative neuroophthalmology practice (BK). Their age ranged from 54 to 78 years (mean 65.4 years); all were white. Fifteen white subjects age 57 to 74 years (mean 65.0 years) with normal findings on ophthalmic examination served as controls. Anterior ischaemic optic neuropathy was diagnosed in an eye with a relative afferent pupillary defect, dyschromatopsia, an acute decrease in visual acuity, or visual field associated with either sectoral disc oedema or generalised disc oedema with peripapillary haemorrhage. Patients were excluded if they had temporal arteritis, previous ocular surgery, or pain on eye movement. No patient had a family history of glaucoma, or recognised ocular hypertension. No patient was being treated with oral medications known to increase intraocular pressure, or receiving topical medications. No patient had signs of pigmentary dispersion syndrome, angle recession, or pseudoexfoliation.

The intraocular pressure was measured hourly for each group by Goldmann applanation tonometry. The first measurement was at 0800 ; subsequent measurements continued until 1600 . Measurements were performed by ophthalmic assistants and resident physicians who were not aware of the nature of the study. The patients were ambulatory throughout the course of the day. As an adjunct to these hourly measurements the intraocular pressure of the 16 study patients was measured at all subsequent visits to determine whether raised intraocular pressure 
not recognised during the 10-hourly measurements might occur. The range of intraocular pressure was defined as the difference between the highest and the lowest of the hourly measurements. ${ }^{17}$ Peak intraocular pressure was defined as the maximum pressure measured during the day. ${ }^{17}$ The mean, peak, and range of intraocular pressure for each patient was determined from the 18 observations available (nine hourly measurements for each of two eyes).

Data were analysed by patient (between involved and non-involved eye) and by group. Data were also analysed by direct comparison between cases and controls, the non-involved eyes being used. Data appeared to be approximately normally distributed within each group, though with higher variance in the ischaemic optic neuropathy group. Therefore between-group analysis of means was performed ( $5 \%$ level of significance) by the separate variance formulation of the $t$ test. ${ }^{18} \mathrm{~A}$ more conservative statistical approach was employed for the other comparisons where the assumption of a normal distribution was doubtful. Within-subject comparisons were made by the Wilcoxon signed rank test, and between-group comparisons were made by the Mann-Whitney rank sum approach. ${ }^{18}$

\section{Results}

Data were analysed separately for the ischaemic optic neuropathy and control groups (Table I). The mean intraocular pressure for the ischaemic optic neuropathy group was $16.7 \mathrm{~mm} \mathrm{Hg}$ as compared with a mean intraocular pressure of $15.3 \mathrm{~mm} \mathrm{Hg}$ for controls $(P=0 \cdot 17)$. The peak intraocular pressure reached during hourly intraocular pressure determinations for the ischaemic optic neuropathy group and controls is illustrated in Figure 1. The peak intraocular pressure exceeded $21 \mathrm{~mm} \mathrm{Hg}$ in five of the ischaemic optic neuropathy patients but none of

TABLE I Intraocular pressure ${ }^{\star}$ in ischaemic optic neuropathy and controls $(\mathrm{mm} \mathrm{Hg})$

Figure 1: Frequency histogram of the peak intraocular pressure during hourly determinations of intraocular pressure in ischaemic optic neuropathy and control population.

\begin{tabular}{|c|c|c|}
\hline Ischaemic optic neuropathy & Controls & p Value \\
\hline $\begin{array}{lr}\text { Mean } & 16.7(3.5) \\
\text { Peak } & 19.9(3.8) \\
\text { Range } & 5.9(2.3)\end{array}$ & $\begin{array}{l}15 \cdot 3(1 \cdot 8) \\
17 \cdot 6(1 \cdot 4) \\
4 \cdot 5(1 \cdot 1)\end{array}$ & $\begin{array}{l}0 \cdot 17 \\
0 \cdot 034 \\
0 \cdot 030\end{array}$ \\
\hline
\end{tabular}

^ Mean (standard deviation) the controls. The mean peak intraocular pressure was $19.9 \mathrm{~mm} \mathrm{Hg}$ for the ischaemic optic neuropathy group versus $17.6 \mathrm{~mm} \mathrm{Hg}$ for controls $(p=0.034)$ (Table I). The intraocular pressure exceeded $21 \mathrm{~mm} \mathrm{Hg}$ during a subsequent visit in two additional patients in whom the hourly determined intraocular pressure peaked at less than $21 \mathrm{~mm} \mathrm{Hg}$. Thus, $44 \%(7 / 16)$ of our ischaemic optic neuropathy group had a recorded intraocular pressure exceeding $21 \mathrm{~mm}$ $\mathrm{Hg}$ during the study period.

The range of intraocular pressure reached during hourly intraocular pressure determinations for the ischaemic optic neuropathy group and controls is illustrated in Figure 2. The range of intraocular pressure was greater for the ischaemic optic neuropathy group $(p=0.030)$. It was 2 to $12 \mathrm{~mm} \mathrm{Hg}$, while for the controls it was 2 to $6 \mathrm{~mm} \mathrm{Hg}$. Eight of 16 ischaemic optic neuropathy patients had a range of intraocular pressures of $6 \mathrm{~mm} \mathrm{Hg}$ or more as compared with only three of 15 controls.

There were no statistically significant differences within each group for right eye-left eye comparisons of standard deviations of mean, peak, or range of intraocular pressure (Table II). Within the ischaemic optic neuropathy group there were no statistically significant differences of peak, mean, or range of intraocular pressure when the involved eye was compared with the non-involved eye.

There was, however, a trend for more variation of intraocular pressure in the involved eye than the non-involved eye $(p=0.056)$. Moreover, there were significant differences in standard deviations for the ischaemic optic neuropathy involved eye versus control eye $(\mathrm{OD}$ and OS) standard deviation $(p=0.024$ and 0.0096 respectively). A direct comparison of the variation in hourly values of intraocular pressure for the ischaemic optic neuropathy non-involved eye was intermediate between the ischaemic optic neuropathy involved eyes and either control eye ( $p=0.075$ and 0.093 respectively).

\section{Discussion}

The cause of non-arteritic anterior ischaemic optic neuropathy has not been established with certainty.' Histological studies in human eyes support the concept of the posterior ciliary circulation as the vascular bed involved in its pathogenesis. ${ }^{19-21}$ The anatomical sites of ischaemic injury in ischaemic optic neuropathy are the prelaminar, laminar and immediate postlaminar region of the optic nerve. The prelaminar and laminar portions of the optic nerve are supplied primarily by the posterior ciliary arteries. These vessels supply the distal nerve both directly and to some extent indirectly through the peripapillary choroidal arteries. ${ }^{22}$ The retrolaminar optic nerve is supplied predominantly by the pial plexus, which receives contributions from the posterior ciliary arteries, extraneural branches of the central retinal artery, and small penetrating branches from numerous orbital arteries. This particular neurovascular anatomy may render these regions especially vulnerable to ischaemic insult and infarction. ${ }^{23}$ It has been described as representing a watershed 


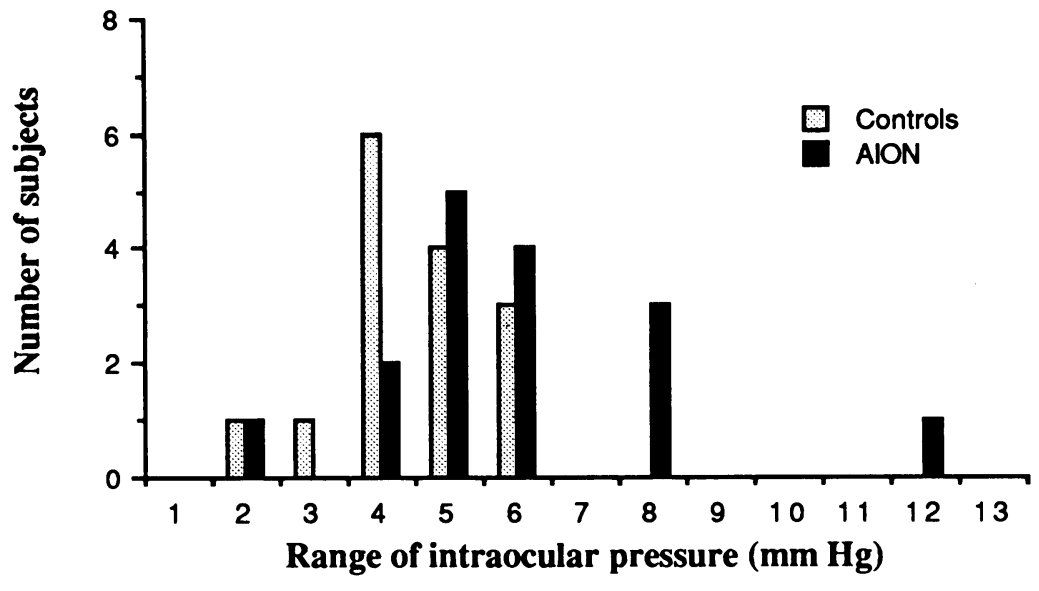

Figure 2: Frequency histogram of the range of intraocular pressure during hourly determinations of intraocular pressure in ischaemic optic neuropathy and control population.

TABLE II Descriptive statistics for within-subject standard deviation of nine consecutive hourly determinations of intraocular pressure

\begin{tabular}{|c|c|c|c|c|c|c|}
\hline \multicolumn{5}{|c|}{ Anterior ischaemic optic neuropathy } & \multirow{2}{*}{\multicolumn{2}{|c|}{$\begin{array}{l}\text { Control } \\
\text { Eye }\end{array}$}} \\
\hline & \multirow{2}{*}{$\begin{array}{l}\text { Involved } \\
\text { Eye }\end{array}$} & \multirow{2}{*}{$\begin{array}{l}\text { Non- } \\
\text { Involved } \\
\text { Eye }\end{array}$} & \multicolumn{2}{|l|}{ Eye } & & \\
\hline & & & $\overline{O D}$ & $O S$ & $\overline{O D}$ & $O S$ \\
\hline Mean & 1.68 & 1.46 & 1.57 & 1.58 & $1 \cdot 26$ & $1 \cdot 18$ \\
\hline Median & 1.67 & 1.47 & 1.63 & 1.56 & 1.23 & $1 \cdot 13$ \\
\hline SD & 0.60 & 0.49 & 0.48 & 0.62 & 0.43 & 0.35 \\
\hline $\operatorname{Max}$ & $3 \cdot 12$ & $2 \cdot 35$ & $2 \cdot 36$ & $3 \cdot 11$ & $2 \cdot 50$ & 1.73 \\
\hline Min & 0.78 & 0.42 & 0.42 & 0.79 & 0.69 & 0.64 \\
\hline
\end{tabular}

zone between the retinal and choroidal circulations. ${ }^{24}$ These regions might therefore be especially susceptible to impaired perfusion states, particularly since the choroidal circulation does not have autoregulatory capabilities (as demonstrated in the cat). ${ }^{25}$ The laminar vessels are unique in being contained within a connective tissue septum, ${ }^{26}$ which may also make them more vulnerable to senile fibrotic changes. Changes have been demonstrated histologically in the posterior ciliary arteries of man in association with atherosclerotic and arteriosclerotic disease. ${ }^{20}$ Furthermore, the laminar and prelaminar vessels are subjected to an especially high extramural pressure owing to the level of intraocular pressure. ${ }^{24}$ Any imbalance produced either by lowering of the perfusion pressure or increase of the intraocular pressure could lead to local ischaemia as the result of compromised blood flow. ${ }^{14}$

All factors concerned with perfusion pressure have prognostic and pathophysiological import as regards the functional integrity of the anterior optic nerve. The deleterious influence of low blood pressure, ${ }^{27} 28$ severe haemodynamic crisis, ${ }^{29}$ and systemic vascular disease, ${ }^{30}$ and the favourable influence of higher levels of blood pressure, ${ }^{27} 28$ have been documented. The anatomical predilection of small, crowded optic nerves, with small cup-disc ratios, to the generation of ischaemic optic neuropathy has been recognised. ${ }^{2-4}$

Raised intraocular pressure may be another factor in some patients. A raised intraocular tension may precipitate enough of a drop in perfusion pressure in the posterior ciliary bed to be haemodynamically significant in the anatomically susceptible patient. The decreased perfusion pressure in the posterior ciliary arteries could lead to ischaemic damage at the level of the laminar and immediately retrolaminar portions of the optic nerve. Such changes have been shown experimentally. ${ }^{31}$ There appears to be preferential involvement of or susceptibility to decreased perfusion in the vessels of the prelaminar region of the optic nerve so that these vessels may suffer ischaemic insult early. ${ }^{32}$ Blumenthal et al have demonstrated that flow ceases in the choroidal circulation of man at intraocular pressures significantly lower than levels required to produce decreased flow within the retinal vascular tree. ${ }^{32}$ They inferred that the peripapillary choroidal vessels and optic disc vessels were the most vulnerable portion of the choroidal circulation to increases in intraocular pressure..$^{32}$ The compact arrangement of neural and vascular elements within an anatomically susceptible scleral canal makes the process of infarction, with resultant oedema, lead to more infarction and oedema. Perfusion in this zone would become especially precarious with higher intraocular pressures.

Our study suggests that high intraocular pressure may be a factor in some patients who develop idiopathic ischaemic optic neuropathy. The peak and the range of variation of the hourly intraocular pressure was greater in the ischaemic optic neuropathy group than in controls. The increased range of variation of intraocular pressure seen in our ischaemic optic neuropathy group is consistent with previous reports which show that the range of intraocular pressure is wider in patients with higher levels of intraocular pressure. ${ }^{33-11}$ Seven of 16 of our patients $(44 \%)$ had an intraocular pressure above $21 \mathrm{~mm} \mathrm{Hg}$. These determinations were recorded between 0800 and 1600 and may not accurately demonstrate the extent of diurnal fluctuation of intraocular pressure. Nevertheless almost half of our ischaemic optic neuropathy group had a raised intraocular pressure - more than seen in our control group or expected from epidemiological population surveys. ${ }^{42} 43$ Though the number of patients studied was small, our findings suggest that high intraocular pressure could be an additional predisposing factor if not an initiating event in the development of non-arteritic anterior ischaemic optic neuropathy in some cases: An alternative interpretation would suggest that the ischaemic event at the nerve head results in ocular hypertension. Our study was not designed to differentiate these two possibilities.

If high intraocular pressure is associated with the occurrence of anterior ischaemic optic neuropathy in some patients, perhaps treatment to lower intraocular pressure might afford some protection for the non-involved eye by improving perfusion pressure in the vessels of that optic nerve head. Such a theoretical basis for intervention has been suggested previously. ${ }^{44}$ It is entirely analogous to the logic behind the institution of steroid therapy in the arteritic variety of ischaemic optic neuropathy, namely, to protect the uninvolved eye. With the availability of relatively selective $\beta-1$ adrenergic blocking agents, which may lower intraocular pressure without constricting peripheral vascular beds or placing the microvasculature at further 
risk for vasoconstriction, ${ }^{45}+6$ such a therapeutic trial seems worth considering.

The authors gratefully acknowledge the assistance, encouragement, and editorial review of Dr Bernard Becker.

1 Quigley HA, Miller NR, Green WR. The pattern of optic nerve fiber loss in anterior ischemic optic neuropathy. $A m \mathcal{F}$ fiber loss in anterior ischem

2 Feit RH, Tomsak RL, Ellenberger C Jr. Structural factors in the development of ischemic optic neuropathy. Am $\mathscr{F}$

3 Beck RW, Savino PJ, Repka MX, Schatz NJ, Sergott RC. Optic disc structure in anterior ischemic optic neuropathy. Ophthalmology 1984; 91: 1334-7.

4 Doro S, Lessell S. Cup-disc ratio and ischemic optic neuropathy. Arch Ophthalmol 1985; 103: 1143-4.

5 Foulds WS. In: Cant JS, ed. Proc. Wm. Mackenzie centenar symp. The ocular circulation in health and disease. London: Kimpton, 1968; 136-41.

6 Foulds WS. Visual disturbances in systemic disorders: Optic neuropathy and systemic disease. Trans Ophthalmol Soc UK 1969; 89: 125-46.

7 Begg IS, Drance SM. Progress of the glaucomatous process related to recurrent ischaemic changes at the optic disc. $E x p$ Eve Res 1971; 11: 141.

8 Begg IS, Drance SM, Sweeney VP. Hemorrhage on the disc sign of acute ischaemic optic neuropathy in chronic simple sign of acute ischaemic optic neuropathy in
glaucoma. Can 7 Ophthalmol 1970; 5: 321-9.

9 Begg IS, Drance SM, Sweeney VP. Ischaemic optic neuropathy in chronic simple glaucoma. Br f Ophthalmol 1971; 55. 73-90.

10 Drance SM, Begg IS. Sector haemorrhage - a probable acute ischaemic disc change in chronic simple glaucoma. Can $\mathcal{F}$ Ophthalmol 1970; 5: 137-41.

11 Sanders MD. Ischaemic papillopathy. Trans Ophthalmol So UK 1971; 91: 369-86.

12 Quigley H, Anderson DR. Cupping of the optic disc in ischemic optic neuropathy. Ophthalmology 1977; 83: 755-62.

13 Katz B, Weinreb NR, Wheeler DT. Ischemic optic neuropathy and intraocular pressure. Ophthalmology 1987; 94 (suppl):

14 Hayreh SS. Anterior ischaemic optic neuropathy. IV. Occurrence after cataract extraction. Arch Ophthalmol 1980; 98: $1410-6$.

15 Douglas GR, Drance S, Schulzer M. The visual field and optic nerve head following acute angle closure glaucoma. Can $\mathscr{f}$ Ophthalmol 1974; 9: 404-7.

16 Sebag J, Thomas JV, Epstein DL, Grant WM. Optic disc cupping in arteritic anterior ischemic optic neuropathy resembles glaucomatous cupping. Ophthalmology 1986; 93 357-61

17 Horie T, Kitizawa Y. The clinical significance of diurnal pressure variation in primary open angle glaucoma. $7 p n$ Ophthalmol 1979; 23: 310-33

18 Dixon WJ, Massey FJ Jr. Introduction to statistical analysis. 3rd d. New York: McGraw-Hill, 1969

19 Lieberman MF, Shahi A, Green WR. Embolic ischemic optic neuropathy. Am F Ophthalmol 1978; 86: 206-10.

20 Ellenberger $\mathrm{C} \mathrm{Jr}$, Netsky MD. Infarction of the optic nerve. F Neurol Neurosurg Psychiatry 1968; 31: 606-11.

21 Anderson DR, Davis EB. Retina and optic nerve after posterior ciliary artery occlusion. Arch Ophthalmol 1974; 92: $422-6$.

22 Lieberman MF, Maumenee AE, Green WR. Histologic studies of the vasculature of the anterior optic nerve. $A m \mathcal{F}$ Ophthalmol 1976; 82: 405-23.
23 Henkind P, Charles NC, Pearson J. Histopathology of ischemic optic neuropathy. Am f Ophthalmol 1970; 69: 78-90.

24 Eagling EM, Sanders MD, Miller SJH. Ischaemic papillopathy. Brf Ophthalmol 1974; 58: 990-1008.

$25 \mathrm{~A} \operatorname{m} \mathrm{A}$, Bill A. The oxygen supply to the retina. II. Effects of high intraocular pressure and of increased arterial carbon dioxide tension on uveal and retinal blood flow in cats. Acto Physiol Scand 1972; 84: 306-19.

26 Anderson DR, Hoyt WF. Ultrastructure of intraorbital portion of human and monkey optic nerve. Arch Ophthalmol 1969; 82: 506 .

27 Lobstein A. Factors affecting the susceptibility of the glaucomatous eye to raised intraocular pressure. First South glaucomatous eye to raised intraocular pressure. First South Ophthalmology. New York, Basel: Karger, 1968

28 Reese AB, McGavic JS. Relation of field contraction to blood pressure in chronic primary glaucoma. Arch Ophthalmol 1942; $27: 845$.

29 Drance SM, Wheeler C, Patullo $M$. Uniocular open angle glaucoma. Am f Ophthalmol 1968; 65: 891-902.

30 Feldman F, Sweeney VP, Drance SM. Cerebro-vascula studies in chronic simple glaucoma. Can $\mathcal{F}$ Ophthalmol 1969 4: 358-64.

31 Hayreh SS. Anterior ischemic optic neuropathy. Berlin: Springer, 1975.

32 Blumenthal M, Gitter KA, Best M, Galin MD. Fluorescein angiography during induced ocular hypertension in man Am f Ophthalmol 1970; 69: 39-43.

33 Amsler $M$. Ueber die allgemeine Richtung der normalen Tonometerkurven. Klin Monatsbl Augenheilkd 1931; 87 $260-2$

34 Cordes FC. Early simple glaucoma. Arch Ophthalmol 1937; 17 896-915

35 Feigenbaum A. Über den Einfluss der Belichtung und Verdunkelung auf den intraokularen Druck normaler und glaukomatoser Augen. Klin Monatsbl Augenheilkd 1928;80 577-95.

36 Hagen S. Glaucoma pressure curves. Acta Ophthalmol (Kbh) 1924: 2: 199-212

37 Koller D Uber die regelmaessigen taglichen Schwankungen des Augendruckes und ihre Ursachen. Arch Augenheilkd 1916; 81: 120-42.

38 Pissarello C. La curva giornaliere della tensione nell'occhio normale e nell'occhio glaucomatoso e influenza di fattori diversi, determinata con il tonometro di Schiøtz. G Accad diversi, determinata con il

39 Thiel R. Klinische Untersuchungen zur Glaukomfrage. Graefes Arch Clin Exp Ophthalmol 1924; 113: 329.

40 Thiel R. Die physiologischen und experimentell erzeugten Schwankungen des intra-okularen Druckes im gesunden und glaukomatosen Auge. Arch Augenheilkd 1925; 96: 331 54.

41 Von Sallmann L, Deutsch A. Die klinische Bedeutung der Tagesdruckkurve und der Belastungsproben bei Glaukom. Graefes Arch Clin Exp Ophthalmol 1930; 124: 624-51.

42 Armaly MF. On the distribution of applanation pressure. I Statistical features and the effect of age, sex and family history of glaucoma. Arch Ophthalmol 1965; 73: 11-8.

43 Loewen U, Handrup B, Redeker A. Results of glaucoma mass screening program. Klin Monatsbl Augenheilkd 1976; 169: 754-66.

44 Hayreh SS. Anterior ischaemic optic neuropathy. III. Treat ment, prophylaxis and differential diagnosis. $\mathrm{Br} \mathcal{F}$ Ophthalmont, prophylaxis and

45 Katz B. Migrainous central retinal artery occlusion. 7 Clin Neuro Ophthalmol 1986; 6: 69-71.

46 Collignon-Brach J, Weekers R. Metoprolol et timolol. $7 \mathrm{Fr}$ Ophtalmol 1981; 4: 275-8. 